\title{
A Long-Run Reflections on Sustainable Development Policies and Solutions
}

\author{
Jari Kaivo-oja* \\ Research Director, University of Turku, Finland
}

Submission: March 08, 2019; Published: April 12, 2019

*Corresponding author: Jari Kaivo-oja, Adjunct Professor, Finland Futures Research Centre, Turku School of Economics, University of Turku, Finland

Keywords: Global environmental; Sustainable development; Technology; Behavioral changes

\section{Mini Review}

A long time ago, in 1993 the Ecologist published a book "Whose Common Future? -Reclaiming the Commons" [1]. The key message of this historical landmark book was that we need to take care of the commons and Brundtland Report (1987) [2] outlined. As most of us know the commons are resources such as streams, forests, street space and public infrastructures like radio wavelengths shared and regulated by the communities that depend directly on them. The critical message of this book was that business and state governments erode the commons and destroy the cultures they support. Local cultures are not allowed to control over their own resources and the scope to run their own affairs. This was the public discussion of "Whose Common Future?" in 1993. Have we made progress on these discussions since 1993? What we should now think about the "our common future(s)"?

Erling Holden et al. [3] published an article in Global Environmental Change about the Brundtland Commission report" Our Common Future" (1987). They liked to revisit the milestone report of sustainability discussion. They noted that still "no clear definition of sustainable development exists to guide politicians in solving challenges at the global or regional levels". They also noted that "the concept's use has increasingly reflected socially desirable attributes of solutions to local- and project-level problems, but these ignore the global challenges that the concept was meant to address". In their article they returned to the original definition of sustainable development used in the Brundtland Report. They suggested an assessment method to determine whether countries currently meet the threshold values of four equally important primary dimensions:

a) Safeguarding long-term ecological sustainability,

b) Satisfying basic needs, and c) Promoting intragenerational and

d) Promoting intergenerational equity. In their paper they showed how 167 countries compare in meeting these threshold values.

The key finding of this study was that no country meets all four thresholds of sustainable development. This result indicates that we need more tailored, and transparent sustainability policies [4-8]. They we also discussing about the future challenges, whether with the use of technology and behavioral changes, will it be possible to reach the threshold values by 2030 .

Another view to sustainability discussion is that private sector should be more responsible and take more care of sustainability. Extreme market liberalists even say that private markets take care of sustainability and no public interventions in favor of sustainability are needed. However, and in spite of this economist's discussion, the role of public sector has been discussed much in the literature of environmental protection and sustainable development. Environmental policies have taken a gradual transition from the so-called end-of-pipe techniques and policies towards preventive environmental policies and further to the more demanding strategies of ecological modernization. All these strategies have had direct implications for the choice of and formation of policy instruments. In the course of time the limitations of traditional command and control policy instruments have become more apparent, both in national and international policy contexts. Today we can note that a shift towards more negotiative and more persuasive regulatory control models have occurred. So called regulatory reform has happened [9]. Control and command models have been substituted in many policy contexts by interactive and cooperative contract models, where citizen participation plays an important role. 
A new IPCC Report, which was published in 2018 [10], has changed public discussion about sustainability challenges. The key message of the IPPC report was that "limiting global warming to $1.5^{\circ} \mathrm{C}$ would require rapid, far-reaching and unprecedented changes in all aspects of society", the IPCC panel (2018) noted. Large expert panel [10] find a consensus and they also noted that "with clear benefits to people and natural ecosystems, limiting global warming to $1.5^{\circ} \mathrm{C}$ compared to $2^{\circ} \mathrm{C}$ could go hand in hand with ensuring a more sustainable and equitable society". The experts of the IPCC report found that limiting global warming to $1.5^{\circ} \mathrm{C}$ would require "rapid and far-reaching" transitions in land, energy, industry, buildings, transport, and cities. The estimate of IPCC Report (2018) was that global net humancaused emissions of carbon dioxide (CO2) would need to fall by about 45 percent from 2010 levels by 2030 , reaching 'net zero' around 2050. New IPCC report (2018) gives policymakers and practitioners the critical information package they need to make decisions that tackle climate change while considering local context and citizen's needs. Common "expert expectation" is now that the next few years (2019-2023) are probably the most important years in our history. This key message of recent IPCC report is very alarming for many influential stakeholder groups and decision-makers. Now we know that not so much time is left for new policy reforms and sustainability start-ups and try-outs. Pivotal moments of decision-makings and new strategies are soon in next five years.

The SDGs are a series of 17 goals that lay out a pathway to a world with diminished inequality, stronger environmental protection and a more sustainable economy. To avoid wrong trade-offs between SDGs we need more critical studies about synergies and trade-offs between key variables of sustainable development [11-13]. In current situation there are risks that positive synergies between targets and policy instruments of SDGs are not strong enough or there can be even negative synergies between desirable SDG targets in national and global sustainability policies. There is also possibility that there is no synergy at all, not positive or negative synergy (see Figure 1).

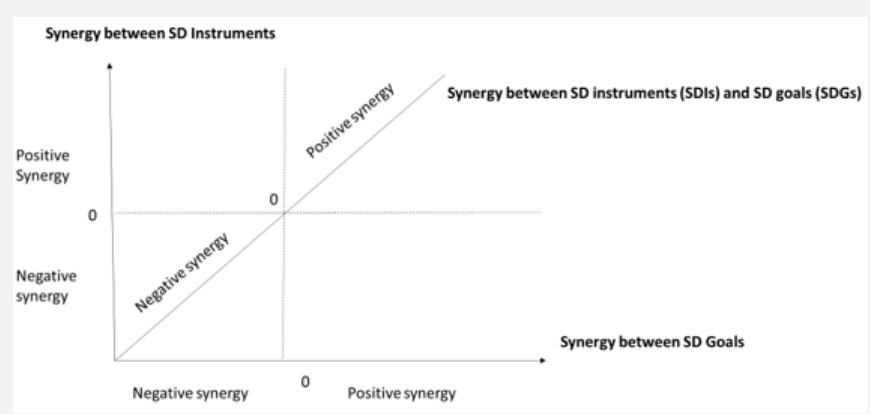

Figure 1: Three critical synergy analyses: SD instruments (SDIs), SD goals (SDGs) and synergy between SD instruments and SD goals.

It is also possible that cyclical nature of sustainability cycles is not analyzed and not understood, which lead to sustainability failures [11]. In different phases of sustainability cycle, some policy instruments may work nicely (leading to SDGs), while some do not work well (not leading to achieve SDGs). It is very important to understand that also synergy varies in time. Sometimes we can measure positive synergy, sometimes synergy can turn to negative synergy and vice versa. There is need to evaluate synergies between goals, instruments and instrumentgoal -trade-offs with different time-series.

Efficient orchestration of sustainability policy needs more scientific attention. As we nowadays know, time for this critical task and real actions, is running out. Climate change policy stress is in the air. Stress to meet the SDGs is also increasing in various societies and networks. With tailored and professionally performed Big Data or Small Data analyses we can solve many wicked problems of sustainable development. Better knowledgebased management and leadership will be needed in the future. We can also eliminate unsustainable patterns of global value networks, which partly create many wicked problems. In this policy planning we can perform tailored Big Data and Small Data analyses. Both quantitative and qualitative analyses are needed [14-16].
Now there is need to find new solutions leading us to stronger sustainability. One critical part of solution is better futures orientation and better futures thinking. Based on historical mistakes, we can note that scientists, scholars, and experts across the full range of academic and professional disciplines can begin to reason more clearly about the future by recognizing and avoiding three conventional problems of futures thinking:

a) The linear projection and predictions,

b) Ceteris paribus -thinking, and

c) Arrival fallacies.

This may in turn lead to more realistic foresight, more accurate projections, and more useful scenario forecasts that acknowledge the radically transformative technological advances that await our civilization over the course of this century [17]. This first reflection is focused of foresight abilities of organizations and institutions. Another focal point and second reflection are the potential existence of change abilities. Although we could have high level of foresight abilities and capacity, there is always a possibility that the level of social change abilities is too low or even not existing. In next years before 2030 the level of change abilities (first critical condition of sustainability) will 
be tested more than just the level of foresight abilities (second critical condition of sustainability). Thinking realistically about possible, probable, and preferable futures is now not enough, we need also actions and better readiness to changes in our economies (global value networks) and social systems (governance systems).

Arrival fallacy means that the future is not just a moving target but an accelerating decision factor which decision-makers will face in various socio-cultural contexts. The key lesson of the arrival fallacy challenge is that we really must clearly and explicitly account for the inherent dynamism of our global coupled human and natural system, whenever we envision possible futures and visions, and the further forward we look the greater care and consideration we must take.

Arrival fallacy problem indicates that time for sustainability reforms can be running out with accelerating decision-making deadlines. In the decision-making of sustainability strategies, we have four scenarios. We must pay more attention to foresight capabilities and change capabilities [18] (Figure 2).

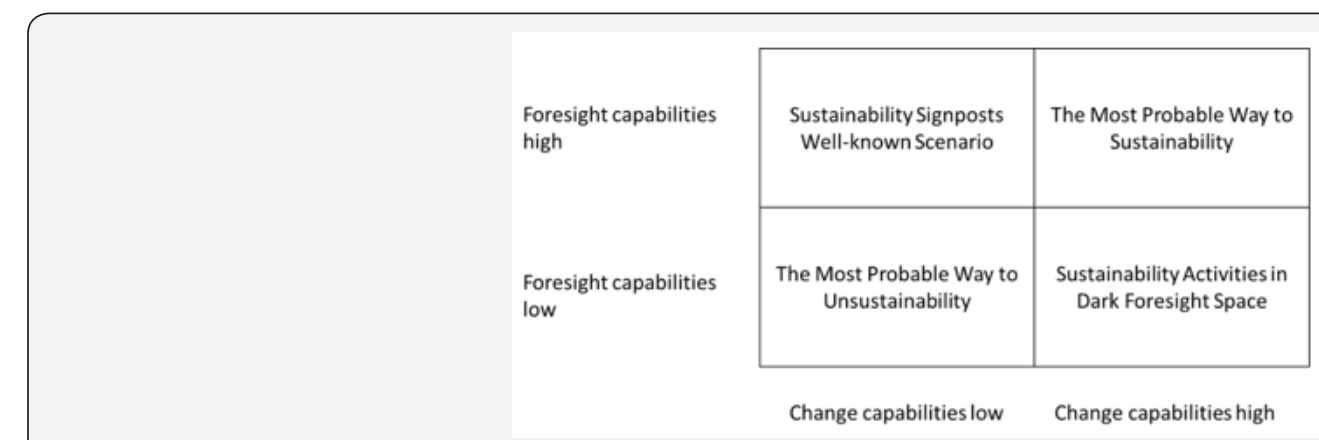

Figure 2: Foresight capabilities and change capabilities. Four scenarios.

First scenario path (Low Foresight Abilities-Low Change Abilities), where foresight abilities and change abilities are both on low levels, is probably leading to unsustainable development path. We can call this scenario "The Most Probable Way to Unsustainability". The second scenario path (High Foresight Abilities-High Change Abilities) is in current situation the most desirable scenario path. We can call this scenario "The Most Probable Way to Sustainability". There are two alternative scenario paths, which are middle-range sustainability paths. Third scenario path (Low Foresight Abilities-High Change Abilities) is meaning that we do notfind righttargets sustainability goals although there is much all kind of sustainability activities and changes. In this scenario we are very active and ready for changes in the "dark jungle" of sustainability options. We can call this scenario "Sustainability Activities in Dark Foresight Space". Fourth scenario path (High Foresight Abilities-Low Change Abilities) is meaning that we have a lot of "fancy" scenarios and foresight reports, but no remarkable activities and real changes. This dominant baseline scenario is what is dominating today's global environmental policy and sustainability discussions. We can call this scenario "Signposts Well-known Scenario" (see Figure 2).

Nowadays most of us are not living in a lovely island like Robinson Crusoe. This is a fundamental social reason why we must find various scenarios and rules for different sociocultural contexts, not only for a lonely island. If we do not live in lonely islands, we need more futures-oriented tools of thinking. Sustainable policy requires more understanding about complexity of societies and eco-systems. Typically, alternative scenarios help us to think complexity. In this short essay, I have presented two critical aspects with simple scenarios: a) The need to analyze synergy between key variables of sustainability policy and

b) The fundamental need to orchestrate our ability concerning foresight abilities and change abilities.

If we shall take these two futures-oriented aspects into serious consideration, we are on the way to smarter sustainability policies.

\section{References}

1. The Ecologist (1993) Whose Common Future? Reclaiming the Commons. New Society Publishers and Earthscan. Philadeplhia PA, USA.

2. WCED (1987) Our Common Future. World Commission on Environment and Development. Oxford University Press, Oxford, USA.

3. Holden E, Linnegrud K, Banister D (2014) Sustainable development: Our Common Future revisited. Global Environmental Change. 26: 130139.

4. Heinonen S, Jokinen P, Kaivo-oja J (2001) The Journal of Forecasting, Planning and Policy 33(3-4): 319-337.

5. Kaivo-oja J (1999) Alternative scenarios of social development: Is analytical sustainability policy analysis possible? How? Sustainable Development 7(3): 140-150.

6. Kaivo-oja J (2001) Scenario learning and potential sustainable development processes in spatial contexts: Towards risk society or ecological modernization scenarios? Futures Research Quarterly 17(2): 33-55.

7. Kaivo-oja J, Luukkanen J, Malaska P (2001) Sustainability evaluation frameworks and alternative analytical scenarios of national economies. Population and Environment 23(2): 193-215.

8. Kaivo-oja J (2002) Social and ecological destruction in the First Class: A plausible social development scenario. Sustainable Development 10(1): 63-66. 
9. Sairinen R (2000) Regulatory reform of Finnish environmental policy. Helsinki University of Technology. Centre for Urban and Regional Studies Publications A27, Espoo.

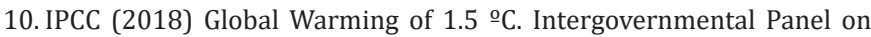
Climate Change, Switzerland.

11. Vehmas J, Kaivo-oja J, Luukkanen J (2016) Sustainability cycles in China, India, and the World? Eastern European Business and Economics Journal 2(2): 139-164.

12. Mainali B, Luukkanen J, Silveira S, Kaivo-oja J (2018) Evaluating synergies and trade-offs among Sustainable Development Goals (SDGs): Explorative analyses of development paths in South Asia and Sub-Sharan Africa. Sustainability 10(3): 815

13. Kaivo-oja J, Vehmas J, Luukkanen J (2014) A Note: De-Growth debate and new scientific analysis of economic growth. Journal of Environmental Protection 5(15): 1477-1481.

This work is licensed under Creative Commons Attribution 4.0 License DOI: 10.19080/IJESNR.2019.18.555987
14. Kuusi O, Kaivo-oja J (2018) Global value producing networks based on the backcasting logic of technology foresight. $6^{\text {th }}$ International Conference on Future-Oriented Technology Analysis (FTA) - Future in the Making, Brussels, p.22.

15. Kaivo-oja J (2019) Introduction: The challenges of Big Data foresight. Lecture notes. Turku Science Park, Turku, Finland.

16. Kaivo-oja J, Panula-Ontto J, Luukkanen J, Vehmas J (2014) Relationships of the dimensions of sustainability as measured by the Sustainable Society Index framework. International Journal of Sustainable Development and World Ecology 21(1): 39-45.

17. Dorr A (2017) Common errors in reasoning about the future: Three informal fallacies. Technological Forecasting and Social Change 116: 322-330.

18. Koskinen J, Kaivo-oja J (2019) Reflections about foresight and change ability.

Your next submission with Juniper Publishers will reach you the below assets

- Quality Editorial service

- Swift Peer Review

- Reprints availability

- E-prints Service

- Manuscript Podcast for convenient understanding

- Global attainment for your research

- Manuscript accessibility in different formats

( Pdf, E-pub, Full Text, Audio)

- Unceasing customer service

Track the below URL for one-step submission https://juniperpublishers.com/online-submission.php 